\title{
Distribution and Phylogeography of Caryopteris incana (Lamiaceae) Based on Chloroplast DNA Sequences in West Kyushu, Japan
}

\author{
Masaya Ando', Kazuaki Kuwabara², Kiyoshi Matsubara ${ }^{3}$, Hitoshi Watanabe ${ }^{3 *}$ \\ ${ }^{1}$ Graduate School of Horticulture, Chiba University, Matsudo, Japan \\ ${ }^{2}$ Faculty of Horticulture, Chiba University, Matsudo, Japan \\ ${ }^{3}$ Center for Environment, Health and Field Sciences, Chiba University, Kashiwa, Japan \\ Email: "hwatanabe@faculty.chiba-u.jp
}

Received 19 December 2015; accepted 25 January 2016; published 28 January 2016

Copyright (C) 2016 by authors and Scientific Research Publishing Inc.

This work is licensed under the Creative Commons Attribution International License (CC BY). http://creativecommons.org/licenses/by/4.0/

\section{Open Access}

\begin{abstract}
Caryopteris incana is a continental plant, transferred to Japan from continental Asia via a land bridge between the Korean Peninsula and Tsushima Islands during a glacial period. It currently grows wild in West Kyushu, Japan. In a previous study, we investigated the distribution of $C$. inca$n a$ in the Tsushima Islands and confirmed the genetic structure of populations by using chloroplast DNA sequence analysis, suggesting that different haplotypes were distributed in the same area. Thus, it seemed that populations of $C$. incana throughout the Tsushima Islands colonized at different times; each haplotype had remained within its population without mixing. In this study, we conducted fieldwork to construct a detailed distribution map in West Kyushu excluding the Tsushima Islands. Additionally, we confirmed genetic structure of the $C$. incana population in these areas by using chloroplast DNA sequence analysis to study the intraspecific phylogenetic relationship of $C$. incana in Japan. We confirmed 37 natural populations in 257 locations throughout West Kyushu excluding the 72 natural populations in the Tsushima Islands. We also confirmed a recent decreasing trend in the number of natural populations in the Nagasaki Mainland. Using the leaves of individuals cultivated from seeds collected from each natural population, we analyzed the chloroplast DNA sequence variations. Among the investigated populations, sequence variations were confirmed in six regions of chloroplast DNA, and those haplotypes were mainly classified into two groups distributed in different areas on the phylogenetic tree. This finding revealed that the common ancestor of $C$. incana in Japan diverged early into two groups, followed by a fragmentation in population distribution for each area. The haplotype network almost reflected the geographical distribution on haplotypes. However, several haplotypes that were distributed in "Corresponding author.
\end{abstract}


other areas were confirmed in the Nagasaki Mainland, suggesting a complicated distribution formation in the past.

Keywords

Caryopteris incana, Intraspecific Differentiation, Chloroplast DNA, Haplotype Network, Vicariance

\section{Introduction}

Biogeography, especially phylogeography, investigates the history of organisms by focusing on generalized information and using genetic variation as an index by employing improved gene technologies [1]. The studies that focus on climate change in the past and the repetition of glacial and interglacial events by using genetic variation from these regions have been conducted for different organisms [2]-[4]. In East Asia, fluctuations in sea levels produce dynamic changes in land configurations during the quaternary glacial period [5]-[9]. This has affected the fragmentation and connection of natural habitats within this area, which result in the plant species richness and endemism in East China, Southern Japan, and the Korean Peninsula [10] [11]. The islands of Japan, located in such a region of East Asia, are a hotspot of distribution changes because of immigration to and emigration from continental Asia.

The Japanese Islands have seen the repeated migration of organisms derived from Mainland China, via connection and fragmentation during glacial periods [12]. Mainland China has repeatedly connected with the Korean Peninsula by a land bridge over the East China Sea (ECS) basin during the Tertiary period and the late Pleistocene age [6] [13]. The Korean Peninsula has been repeatedly connected with Northwest Kyushu and Honshu by a land bridge between the South Korean Peninsula and Tsushima from the early Pleistocene age to the late Pleistocene age [8]. In these areas, West Kyushu, located near many continental islands, has had repeated immigration of continental species and emigration of endemic species, by multiple routes during different periods, and thus these areas have received attention owing to their unique floral composition [14]. Many species of the continental plants, emigrating from Mainland China to Japan through the Korean Peninsula, have extended distribution through the land bridge, which is made by falling sea levels during the glacial periods. These populations are fragmented by rising sea levels and have survived [15]. Caryopteris incana (Thunb.) Miq. is one such species of a continental plant growing wild to the islands of Nagasaki and Kagoshima in Japan.

Caryopteris incana is a perennial herb, shrub, or subshrub that is distributed in China, the Korean Peninsula, and Japan. It is a short-day plant; lavender-blue, cymose flowers in each axil of the opposite leaf appear naturally from September to October and continue to flower for one to two months. It is mainly observed on sunny, bare rock. It has the character of the chasmophyte plant, which grows on the rock slits that have accumulated soil and organic matter; Selaginella is recognized as the part of the same community [16]. Because of the features of the natural environment, it has been confirmed that each population is discontinuously separated. Populations of $C$. incana have decreased because of human development around its natural habitat, and it has been designated as endangered species, listed as "vulnerable" in Japan [17].

Because detailed fieldwork related to C. incana in West Kyushu has not been conducted since 1988, we have performed our investigation in Tsushima, Nagasaki, which is assumed a center of its distribution [18]. In the previous study, we confirm that $C$. incana is widely distributed in each site throughout the Tsushima Islands, and 72 natural populations are located in open rocky sites. Additionally, using the leaves of individuals cultivated from seeds collected from each natural population, we analyzed the sequence variation of the chloroplast DNA. As a result, we confirmed sequence variations among the populations in six regions of chloroplast DNA. However, the genetic variation in the Tsushima Islands was too little, and thus we cannot construct reliable family trees among haplotypes and discuss the change of distribution. Its distribution in the Japanese Islands is limited to West Kyushu [9] [19]. According to Kimura [6], these areas have been exposed during the Last Glacial Maximum (LGM), and it is speculated that the distribution of populations was expanded and fragmented until the present. Therefore, by analyzing the genetic structure of the populations distributed in these areas and by revealing the phylogenetic relationships, we can obtain phylogeographical information for $C$. incana. In addition, fieldwork in West Kyushu excluding the Tsushima Islands, has not been conducted since 1988 [16], and C. in- 
cana is in danger of extinction, particularly on the Koshikijima Islands. Thus, the confirmation of the current status of reported populations, and fieldwork to identify new populations at bare rock locations where C. incana would be expected to grow will provide necessary information for conservation.

We performed this study with two purposes: to construct a detailed distribution map of C. incana, an endangered species of West Kyushu via fieldwork, and to assess the genetic structure of each population in West Kyushu using DNA sequencing and then compare its structure with the geographical structure. Consequently, these results would offer useful information for current distributions of C. incana in West Kyushu and clear geographical variation in populations distributed over each area.

\section{Materials and Methods}

\subsection{Field Work}

We have confirmed 72 natural populations by conducting fieldwork in the Tsushima Islands, Nagasaki [18]. In this study, we investigated the Nagasaki Mainland, Goto Islands, some remote islands, and the western parts of Saga adjacent to the Nagasaki and Koshikijima Islands, based on the report by Itow and Kawasato [16] (Figure 1). When groups of individuals were separated by more than $2 \mathrm{~km}$, we defined each as a different "population". We confirmed the current status of natural populations reported by Itow and Kawasato [16] and investigated locations of bare rock where $C$. incana would be expected to grow. We recorded environmental data, such as the latitude/longitude, altitude, and approximate number of individuals in each natural population. Additionally, for the genetic investigation of each population, we collected seeds from mature individuals in all populations.

\subsection{Sampling and DNA Extraction}

The management of plant samples from seeds collected from each natural population for the investigations, and the extracting method from the leaves of individuals cultivated followed the previous report [18].

\subsection{DNA Sequence Analyses}

To investigate the chloroplast DNA sequences, we used three regions that were registered in Genbank under $C$. incana that were suitable for phylogenetic analysis, and were more subtle than variation within the genus; matK, $\operatorname{trnL}$-trnF, and rpl32-trnL. Therefore, we investigated four intergenic spacer sequences that were used in the previous report and were determined to be suitable for the classification of closely related species by Shaw et al. [20]. Each primer was newly prepared from the original paper or sequence information in Genbank registration regions, and universal primers were used for the remaining regions. The PCR condition, the sequences of primers used, and the equipment used were similar to the former report [18].

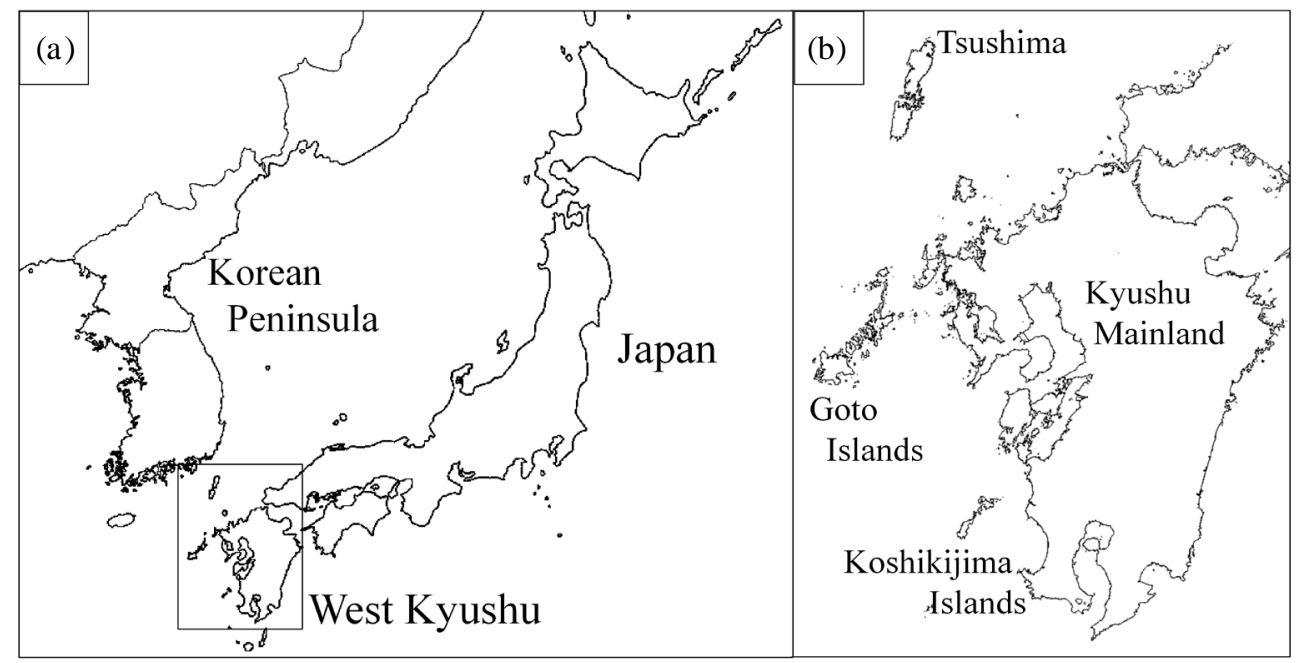

Figure 1. Map showing the location of the study area. (a) Geographical location of West Kyusyu, Japan. (b) Outline of West Kyusyu. 


\subsection{Phylogenetic Analyses}

To compare all populations of West Kyushu, we added the base sequences of 72 populations from the Tsushima Islands that were investigated in the former report to the phylogenetic analyses. The base sequences of each population were aligned using the BioEdit software (version 7.2.5) and compared with the registration sequences in the Genbank registration region [21]. Phylogenetic trees were constructed by the neighbor-joining method using the Kimura 2-parameter model in MEGA 6 [22]. The reliability of the topology was assessed with a bootstrap analysis using 10,000 replications. Tripora divaricate (Maxim.) P.D. Cantino, which is a related genus of Caryopteris, was included as outgroup in the phylogenetic analysis. The network figure was drawn using the TCS 1.21 software package, which is able to analyze the insertion-deletion (indel) along with the substitution [23].

\section{Results}

\subsection{Local Environments}

During our fieldwork, we investigated 257 locations throughout West Kyushu, excluding the Tsushima Islands, that were suitable for the growth of $C$. incana (Nagasaki Mainland = 146; Goto Islands = 80; Koshikijima $=31$ ). As a result, we confirmed 37 natural populations (Table 1): 16 populations in the Nagasaki Mainland, 16 populations in the Goto Islands, and 5 populations in the Koshikijima Islands were confirmed (Figures 2(a)-(c)). The average altitude of these locations was $24.9 \pm 3.8$ (mean \pm S.D.) $\mathrm{m}$ for the Tsushima Islands [18], $175.3 \pm 26.9$ $\mathrm{m}$ in Nagasaki Mainland, $35.75 \pm 7.77 \mathrm{~m}$ for the Goto Islands, and $123.8 \pm 22.0 \mathrm{~m}$ for the Koshikijima Islands. On Iki Island, Nagasaki, we were not able to confirm the natural population according to Itow and Kawasato [16]. Among the survey areas, 6 populations were distributed along the shore of the Goto Islands, and several populations were confirmed in the environment near villages, including the open rocky sites along the roadside, like the Tsushima Islands. The populations in the southern part of the Goto Islands tended to include fewer individuals within a population; the populations in the northern part tended to include more individuals within a population. However, the populations in the Nagasaki Mainland, except one population along the shore, were located in the inland and particularly limited to high altitudes. In the Nagasaki Mainland, the populations near Nagasaki City tended to include fewer individuals than populations on Hirado Island of northwestern Nagasaki. In eastern Nagasaki, and on the eastern side of the neighborhood of Saga, no natural populations were confirmed in the environment suitable for the growth of $C$. incana. On the Koshikijima Islands, there were fewer numbers of populations than other areas; only one population was confirmed on the south island of the Koshikijima Islands. There were many individuals in one population (C107) on the south island of the Koshikijima Islands, but the populations on the north and center island tended to include fewer individuals. In addition, one population (C106), which included many individuals on the north island of the Koshikijima Islands, was located near the green slope faces along the roadside, and it is possible that those were affected by human activities. The populations in West Kyushu tended to have fewer individuals and population densities than the populations on the Tsushima Islands, thus isolated populations which had fewer opportunities to exchange genes with other populations were presumed to have lower fitness due to inbreeding or Allee effect [24]-[26].

According to the report by Itow and Kawasato [16], there were 26 natural populations of C. incana in West Kyushu, excluding the Tsushima Islands. The populations that we were not able to confirm in this study were at 12 locations reported by Itow and Kawasato [16]. Ten of these were located in the Nagasaki Mainland, suggesting a decreased number of natural populations in this area. Among the survey areas, the distribution of $C$. incana in Hisakajima in the Goto Islands, Azuchioshima in the northern Nagasaki Mainland, and Naka-Koshikijima of the Koshikijima Islands had not been previously reported and were confirmed as new natural populations.

\subsection{Sequence Variations}

Sequence variations among populations in six of the chloroplast DNA samlpes were confirmed using primers prepared from the Genbank registration sequences, or universal primers. The intergenic spacer sequence of the trnL-trnF region distinguished three groups by a sequence variation in the number of repetitions (Table 2). Similarly, the sequence of the rpl32-trnL region distinguished five groups by such variation. The sequence of the $p s b \mathrm{D}$-trn $\mathrm{T}$ region distinguished five groups by sequence variations in the number of repetitions, and three groups by two sites of indels of 9 and 7 bases. The sequence of the $n d h F-r p l 32$ region distinguished two groups 
Table 1. Latitude, longitude, altitude, and number of individuals of study populations in Caryopteris incana.

\begin{tabular}{|c|c|c|c|c|c|}
\hline Population & Local area & North latitude & East longitude & Altitude (m) & Number of individuals \\
\hline $\mathrm{C} 73$ & Nagasaki Mainland & $32^{\circ} 43^{\prime} 52^{\prime \prime}$ & $129^{\circ} 54^{\prime} 57^{\prime \prime}$ & 340 & $<20$ \\
\hline $\mathrm{C} 74$ & Nagasaki Mainland & $32^{\circ} 46^{\prime} 3^{\prime \prime}$ & $129^{\circ} 51^{\prime} 11^{\prime \prime}$ & 100 & $100<$ \\
\hline $\mathrm{C} 75$ & Nagasaki Mainland & $33^{\circ} 24^{\prime} 6^{\prime \prime}$ & $129^{\circ} 32^{\prime} 52^{\prime \prime}$ & 193 & $<20$ \\
\hline C76 & Nagasaki Mainland & $33^{\circ} 10^{\prime} 37^{\prime \prime}$ & $129^{\circ} 22^{\prime} 17^{\prime \prime}$ & 255 & $20-100$ \\
\hline C77 & Nagasaki Mainland & $33^{\circ} 12^{\prime} 51^{\prime \prime}$ & $129^{\circ} 23^{\prime} 32^{\prime \prime}$ & 178 & $100<$ \\
\hline C78 & Nagasaki Mainland & $33^{\circ} 20^{\prime} 1^{\prime \prime}$ & $129^{\circ} 26^{\prime} 52^{\prime \prime}$ & 108 & $100<$ \\
\hline C79 & Nagasaki Mainland & $33^{\circ} 13^{\prime} 32^{\prime \prime}$ & $129^{\circ} 27^{\prime} 25^{\prime \prime}$ & 114 & $100<$ \\
\hline $\mathrm{C} 80$ & Nagasaki Mainland & $33^{\circ} 12^{\prime} 5^{\prime \prime}$ & $129^{\circ} 24^{\prime} 5^{\prime \prime}$ & 23 & $100<$ \\
\hline C81 & Nagasaki Mainland & $33^{\circ} 21^{\prime} 5^{\prime \prime}$ & $129^{\circ} 29^{\prime} 18^{\prime \prime}$ & 52 & $20-100$ \\
\hline C82 & Nagasaki Mainland & $33^{\circ} 18^{\prime} 37^{\prime \prime}$ & $129^{\circ} 39^{\prime} 60^{\prime \prime}$ & 333 & $20-100$ \\
\hline C83 & Nagasaki Mainland & $33^{\circ} 1 ' 29^{\prime \prime}$ & $129^{\circ} 36^{\prime} 13^{\prime \prime}$ & 9 & $20-100$ \\
\hline C84 & Nagasaki Mainland & $32^{\circ} 50^{\prime} 5^{\prime \prime}$ & $129^{\circ} 42^{\prime} 26^{\prime \prime}$ & 164 & $<20$ \\
\hline C85 & Nagasaki Mainland & $32^{\circ} 48^{\prime} 37^{\prime \prime}$ & $129^{\circ} 47^{\prime} 53^{\prime \prime}$ & 317 & $<20$ \\
\hline C86 & Nagasaki Mainland & $32^{\circ} 49^{\prime} 51^{\prime \prime}$ & $129^{\circ} 53^{\prime} 40^{\prime \prime}$ & 220 & $20-100$ \\
\hline $\mathrm{C} 87$ & Nagasaki Mainland & $32^{\circ} 46^{\prime} 7^{\prime \prime}$ & $129^{\circ} 53^{\prime} 1 "$ & 276 & $20-100$ \\
\hline C88 & Goto Islands & $32^{\circ} 42^{\prime} 37^{\prime \prime}$ & $128^{\circ} 39^{\prime} 24^{\prime \prime}$ & 12 & $<20$ \\
\hline C89 & Goto Islands & $32^{\circ} 48^{\prime} 32^{\prime \prime}$ & $128^{\circ} 56^{\prime} 42^{\prime \prime}$ & 46 & $20-100$ \\
\hline C90 & Goto Islands & $32^{\circ} 50^{\prime} 8^{\prime \prime}$ & $128^{\circ} 57^{\prime} 14^{\prime \prime}$ & 6 & $100<$ \\
\hline C91 & Goto Islands & $32^{\circ} 42^{\prime} 53^{\prime \prime}$ & $128^{\circ} 50^{\prime} 31^{\prime \prime}$ & 3 & $<20$ \\
\hline C92 & Goto Islands & $32^{\circ} 51^{\prime} 59^{\prime \prime}$ & $129^{\circ} 4^{\prime} 32^{\prime \prime}$ & 54 & $100<$ \\
\hline C93 & Goto Islands & $32^{\circ} 53^{\prime} 35^{\prime \prime}$ & $129^{\circ} 5^{\prime} 13^{\prime \prime}$ & 2 & $100<$ \\
\hline C94 & Goto Islands & $32^{\circ} 54^{\prime} 41^{\prime \prime}$ & $129^{\circ} 5^{\prime} 27^{\prime \prime}$ & 8 & $100<$ \\
\hline C95 & Goto Islands & $33^{\circ} 7^{\prime} 32^{\prime \prime}$ & $129^{\circ} 6^{\prime} 10^{\prime \prime}$ & 71 & $<20$ \\
\hline C96 & Goto Islands & $33^{\circ} 2^{\prime} 36^{\prime \prime}$ & $129^{\circ} 5 ' 51^{\prime \prime}$ & 51 & $100<$ \\
\hline C97 & Goto Islands & $32^{\circ} 58^{\prime} 7^{\prime \prime}$ & $129^{\circ} 10^{\prime} 3^{\prime \prime}$ & 96 & $<20$ \\
\hline C98 & Goto Islands & $32^{\circ} 57^{\prime} 44^{\prime \prime}$ & $129^{\circ} 0^{\prime} 20^{\prime \prime}$ & 84 & $100<$ \\
\hline C99 & Goto Islands & $32^{\circ} 52^{\prime} 7^{\prime \prime}$ & $129^{\circ} 2^{\prime} 45^{\prime \prime}$ & 2 & $100<$ \\
\hline C100 & Goto Islands & $32^{\circ} 51^{\prime} 16^{\prime \prime}$ & $129^{\circ} 2^{\prime} 54^{\prime \prime}$ & 15 & $20-100$ \\
\hline C101 & Goto Islands & $32^{\circ} 44^{\prime} 19^{\prime \prime}$ & $128^{\circ} 46^{\prime} 41^{\prime \prime}$ & 25 & $<20$ \\
\hline C102 & Goto Islands & $32^{\circ} 36^{\prime} 24^{\prime \prime}$ & $128^{\circ} 43^{\prime} 28^{\prime \prime}$ & 58 & $20-100$ \\
\hline C103 & Koshiki Islands & $31^{\circ} 49^{\prime} 33^{\prime \prime}$ & $129^{\circ} 54^{\prime} 39^{\prime \prime}$ & 195 & $<20$ \\
\hline C104 & Koshiki Islands & $31^{\circ} 48^{\prime} 47^{\prime \prime}$ & $129^{\circ} 53^{\prime} 10^{\prime \prime}$ & 94 & $<20$ \\
\hline C105 & Koshiki Islands & $31^{\circ} 48^{\prime} 8^{\prime \prime}$ & $129^{\circ} 50^{\prime} 0^{\prime \prime}$ & 156 & $<20$ \\
\hline C106 & Koshiki Islands & $31^{\circ} 52^{\prime} 22^{\prime \prime}$ & $129^{\circ} 51^{\prime} 49^{\prime \prime}$ & 87 & $100<$ \\
\hline C107 & Koshiki Islands & $31^{\circ} 38^{\prime} 55^{\prime \prime}$ & $129^{\circ} 43^{\prime} 24^{\prime \prime}$ & 87 & $100<$ \\
\hline C108 & Goto Islands & $32^{\circ} 49^{\prime} 67^{\prime \prime}$ & $128^{\circ} 51^{\prime} 63^{\prime \prime}$ & 39 & $<20$ \\
\hline C109 & Nagasaki Mainland & $33^{\circ} 29^{\prime} 92^{\prime \prime}$ & $129^{\circ} 32^{\prime} 63^{\prime \prime}$ & 123 & $100<$ \\
\hline \multicolumn{6}{|c|}{ The average altitude of each area indicate below. } \\
\hline & Nagasaki Mainland & & & $175.3 \pm 26.9 *$ & \\
\hline & Goto Islands & & & $35.75 \pm 7.77$ & \\
\hline & Nagasaki Mainland & & & $123.8 \pm 22.0$ & \\
\hline \multicolumn{6}{|c|}{${ }^{*}$ mean \pm S.D. } \\
\hline
\end{tabular}




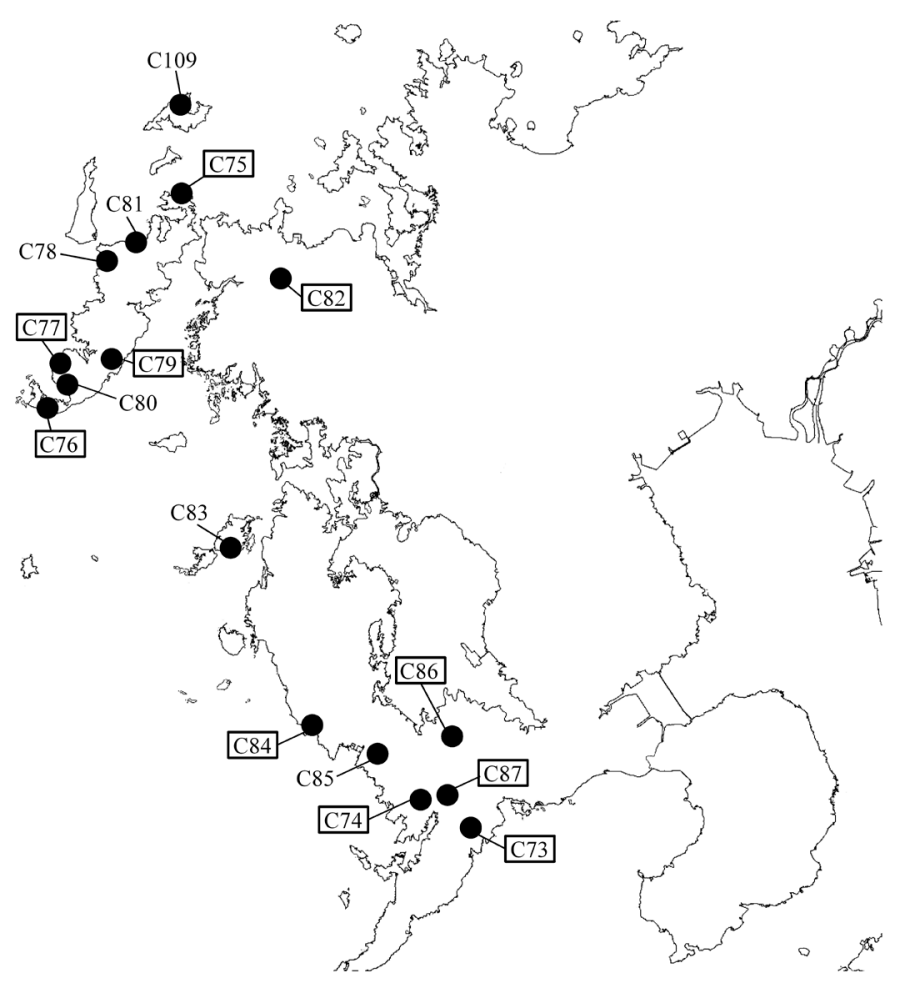

(a)

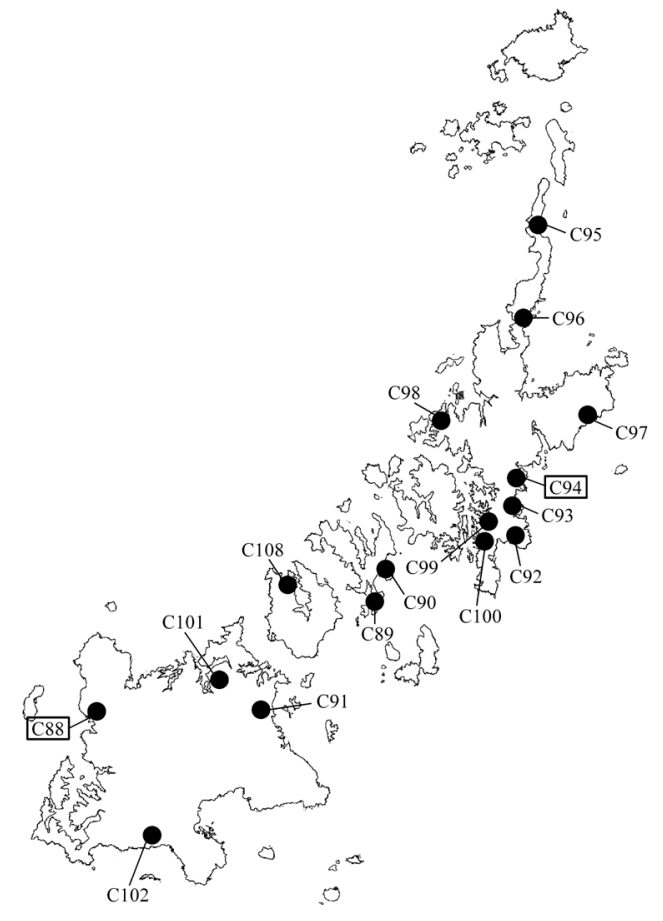

(b)

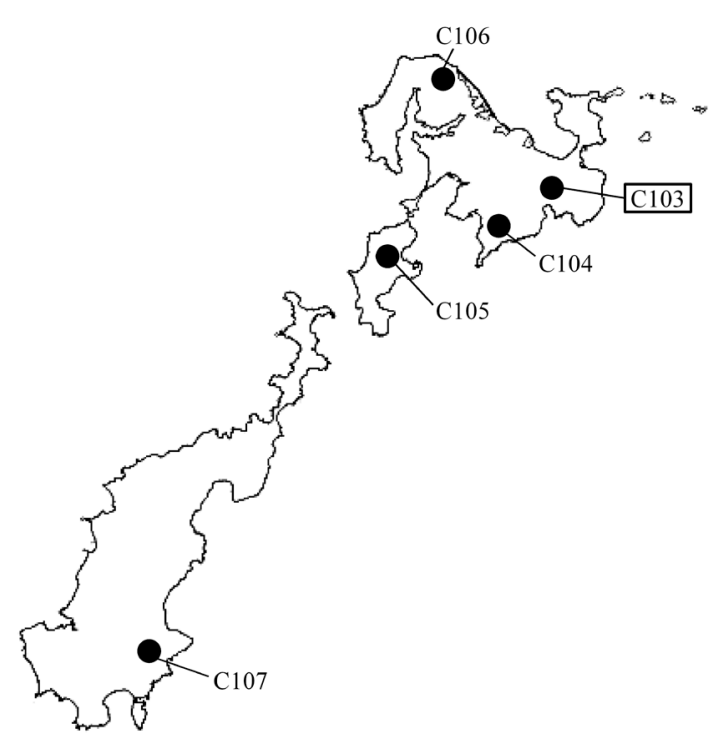

(c)

Figure 2. (a). Geographic distribution of Caryopteris incana on the Nagasaki Mainland. Black circles indicate each population. Numbers label different populations. Boxed labels indicate populations reported by Itow and Kawasato [16]. (b). Geographic distribution of Caryopteris incana in Goto Islands. Black circles indicate each population. Numbers label different populations. Boxed labels indicate populations reported by Itow and Kawasato [16]. (c). Geographic distribution of Caryopteris incana on the Koshikijima Islands. Black circles indicate each population. Numbers label different populations. Boxed labels indicate populations reported by Itow and Kawasato [16]. 


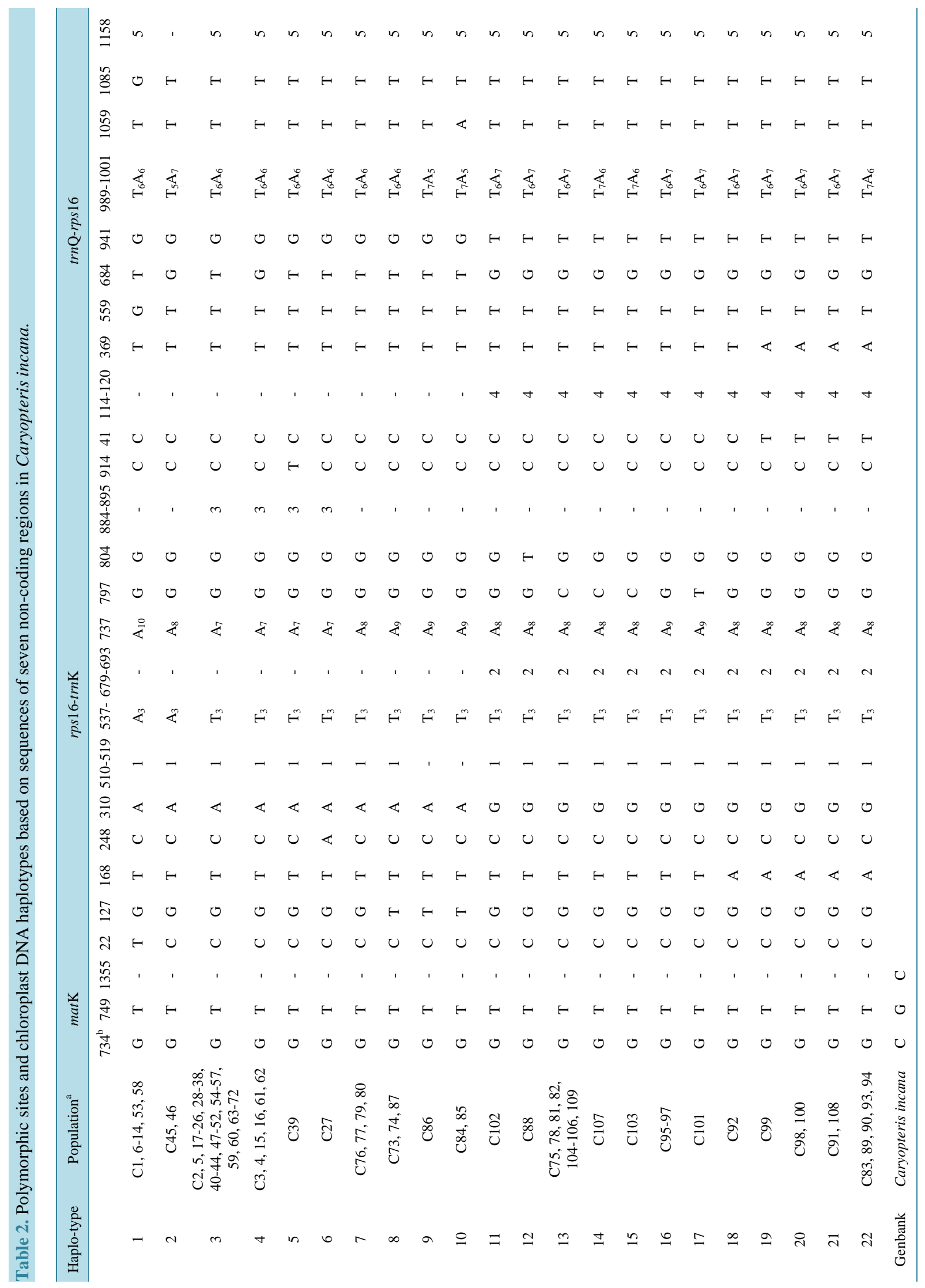




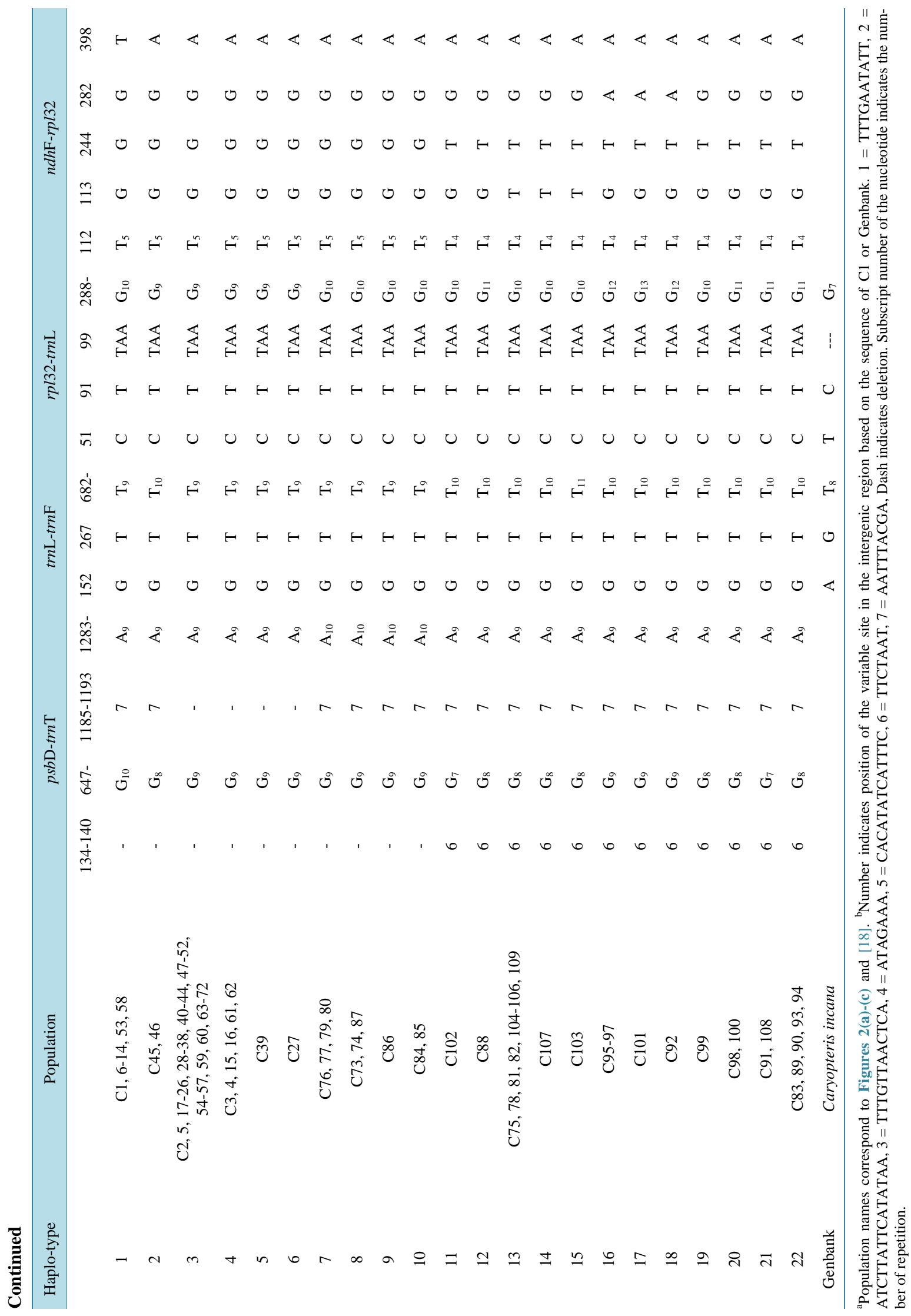


by sequence variations in the number of repetitions, and five groups by four substitution sites. The sequence of the trnQ-rps16 region distinguished five groups by sequence variations in the number of repetitions, three groups by two sites of indels of 7 and 13 bases, and six groups by seven substitution sites. The sequence of the rps16-trnK region distinguished four groups by sequence variations in the number of repetitions, four groups by three sites of indels of 10,12 and 15 bases, and distinguished eleven groups by nine substitution sites. The sequences variations in total comprising seven sites of repetitions, seven sites of indels, and twenty substitution sites were confirmed between 109 populations of $C$. incana.

The geographical distribution for each haplotype of chloroplast DNA sequences in the study areas are shown in Figure 3. In each area, five haplotypes were located on the Tsushima Islands [18] (Figure 3(a)). Two haplotypes were mainly separated between the southern part and the northern part of the Tsushima Islands, and several haplotypes were located in the center part and the north island. Six haplotypes were located in the Nagasaki Mainland (Figure 3(b)). Nine haplotypes were located on the Goto Islands (Figure 3(c)). Three haplotypes were located on the Koshikijima Islands (Figure 3(d)).

\subsection{Phylogenetic Analyses}

The family tree consisted of 22 haplotypes from 109 natural populations in West Kyushu, and is shown in Figure 4. These haplotypes were mainly classified into two groups. The lower group on the family tree was designated from H1 to H10. These haplotypes were distributed on the Tsushima Islands and the Nagasaki Mainland. The upper group on the family tree was designated from H11 to H22. These haplotypes were distributed on the Goto Islands, Koshikijima Islands, and the Nagasaki Mainland. The haplotype network that included the indels of base sequences, and the number of repetitions along with the substitutions, is showed in Figure 5. The haplotype network almost reflected the geographical distribution of haplotypes.

\section{Discussion}

\subsection{Sequence Variations}

Like the sequence variation of the populations on the Tsushima Islands [18], several substitution sites between Genbank registration sequences and those of the study populations were confirmed in the matK, trnL-trnF and rpl32-trnL regions(Table 2). However, there were no indications of substitution among the study populations in these sites. In Carex conica, haplotypes of chloroplast DNA that included trnL-trnF were common in the Kyushu Mainland, Tsushima Islands, and Jeju Island, Korea, which suggested the result of rapid postglacial expansion from a few refugia in Kyushu [27]. Therefore, the substitutions among the study populations were not confirmed like in the previous study [18], suggesting that the distribution of C. incana in West Kyushu might have formed relatively recently.

The number of haplotypes distributed in Goto Islands was the largest of all, suggesting that the genetic diversity within this area was rich. Additionally, different haplotypes were confirmed among the nearby populations within an island (Figure 3(c)), suggesting that the fragmentation of each population within this area, and each varied haplotype, was maintained in each population. One population in the center part of Nagasaki Mainland was confirmed as the haplotype that was distributed on the Goto Islands (Figure 3(b), Figure 3(c)). This population was only located in rocky places facing the sea within this area. Moreover, one of haplotypes that was distributed in the northwestern area matched the haplotype distributed on the Koshikijima Islands (Figure 3(b), Figure 3(c)). The population survey showed that this haplotype was located on bare rocky sites, such as the top of a mountain or a natural rock face, and it did not seem to be affected by human activities, such as planting. Thus, we speculated that the populations in the Nagasaki Mainland maintained their origins.

\subsection{Phylogenetic Analyses}

Overall, low bootstrap values, indicating the reliability of the family tree (Figure 4), were shown, suggesting a low level of relationship between the sequences. $\mathrm{H7}$ to H10, from the northwestern and southern part of the Nagasaki Mainland, were suggested to be closely related with $\mathrm{H} 3$ in the northern part of the Tsushima Islands. However, it seemed that $\mathrm{H} 1$ and $\mathrm{H} 2$ from the Tsushima Islands had separated earlier which resulted in each haplotype. From this, H13 to H15 on the Koshikijima Islands, and in the northwestern part of the Nagasaki Mainland, were designated as a different sub-group on the Goto Islands, suggesting that these haplotypes had 


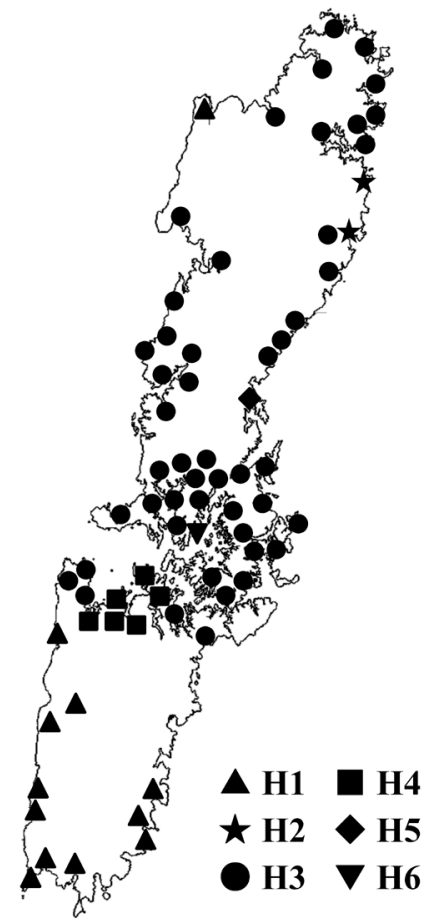

(a)

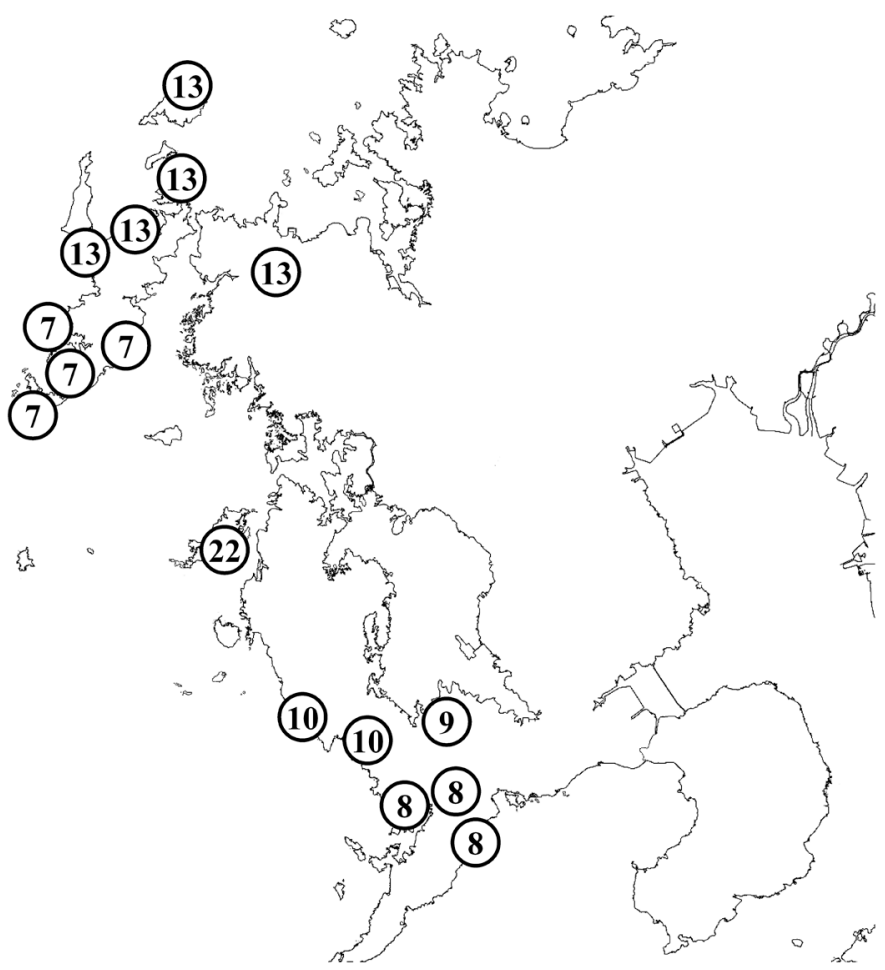

(b)

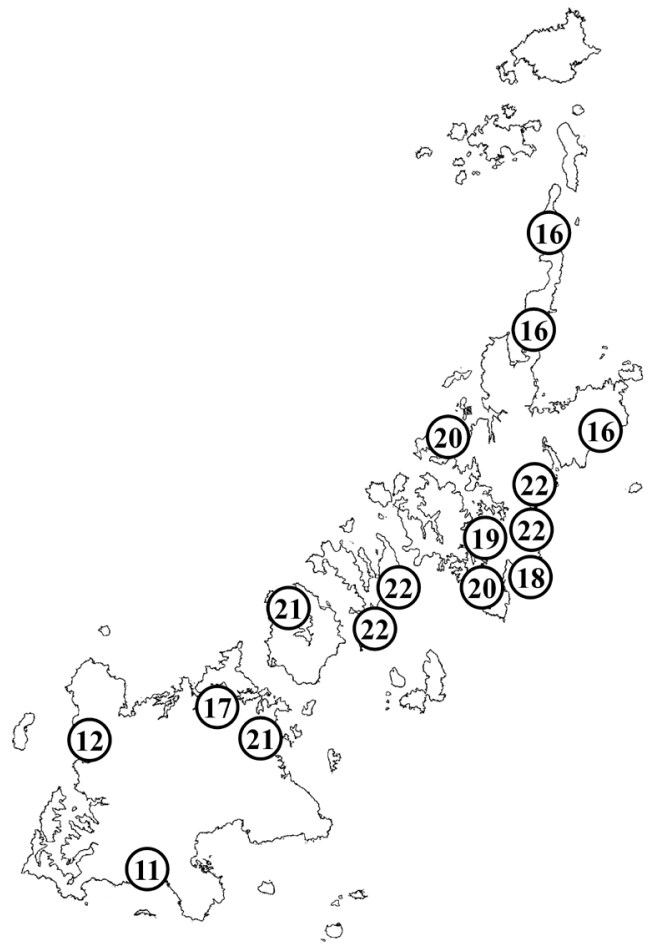

(c)

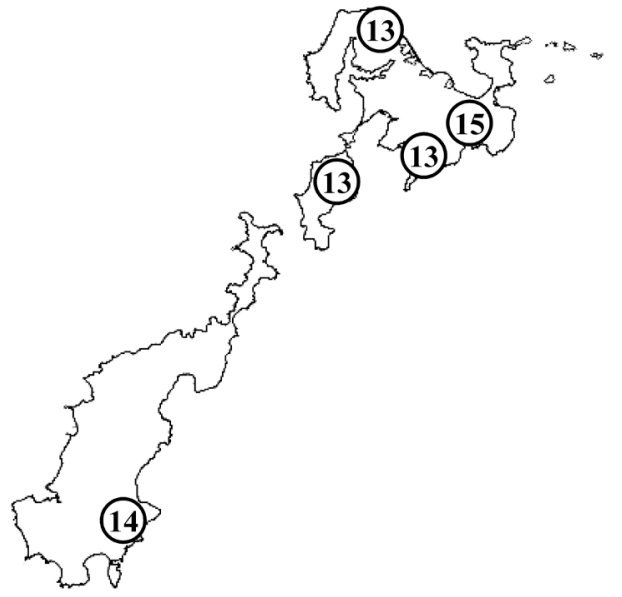

(d)

Figure 3. (a). Geographic distribution of chloroplast DNA haplotypes detected on the Tsushima Islands [18]. (b). Geographic distribution of chloroplast DNA haplotypes detected in the Nagasaki Mainland. Circle labels indicate chloroplast DNA haplotypes corresponding to Table 2. (c). Geographic distribution of chloroplast DNA haplotypes detected on the Goto Islands. Circle labels indicate chloroplast DNA haplotypes corresponding to Table 2. (d). Geographic distribution of chloroplast DNA haplotypes detected on the Koshikijima Islands. Circle labels indicate chloroplast DNA haplotypes corresponding to Table 2. 


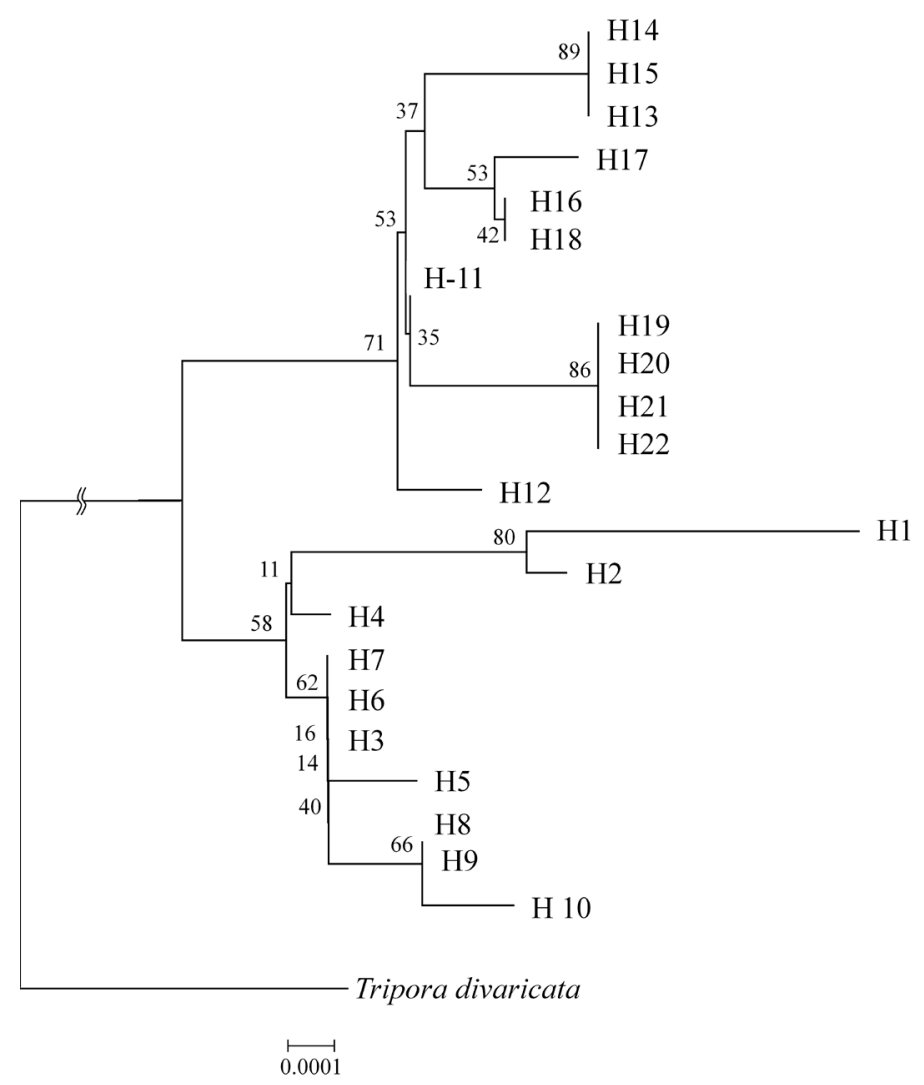

Figure 4. Neighbor-joining tree of chloroplast DNA haplotypes based on the sequences of six non-coding regions in Caryopteris incana. Numbers below the branches indicate the bootstrap values. Scale bar indicates the number of nucleotide substitutions per site.

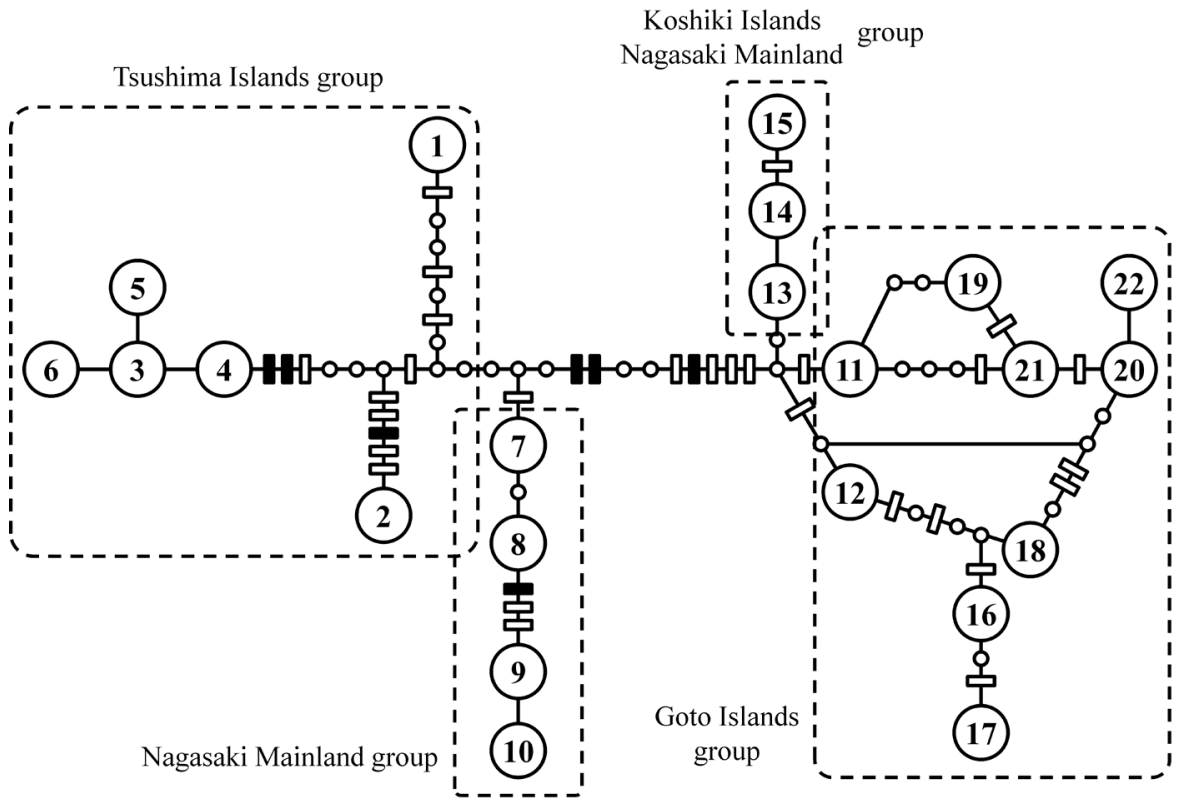

Figure 5. Haplotype network among all West Kyushu haplotypes in Caryopteris incana. Haplotype numbers correspond to Table 2. Small circles indicate nucleotide substitutions. Solid and open bars indicated indels of the set and one nucleotide, respectively. 
separated earlier than the diverging haplotypes of the Goto Islands.

The Goto Island group included the richest haplotype network (Figure 5), suggesting that the current distribution had been formed by maintaining the isolated populations, which were separated early within this area. As a whole, it seemed that the haplotypes were mainly separated near the center part of the network by several indels of base sequences and substitutions. Because these classifications indicated a similar result within the family tree, we speculated that the common ancestor of $C$. incana in Japan diverged into two groups near center part of haplotype network. Several phylogeographical studies in these areas had suggested a southward transfer during the LGM, followed by a northward transfer during the period of de-glaciation [28] [29]. From this, it was suggested that $C$. incana transferred southward from the Korean Peninsula to the Goto Islands and the Nagasaki Mainland, with the decrease in temperature during the glacial period, followed by an expansion northward or southward to each area. Furthermore, a nested structure did not form among haplotypes between each area, suggesting that the two groups diverged into each area; after that, the differentiation between haplotypes within each area developed. Thus, the genetic composition in these areas would have been formed by the effects of vicariance and migration through historical processes that were linked to the fluctuations of sea levels during the late Pleistocene. The haplotype of the northern part of the Nagasaki Mainland that was distributed on the Koshikijima Islands was different from the other haplotypes distributed in the Nagasaki Mainland; thus, it seemed that the current distribution of the populations in this area was established by a different process. The natural population of C. incana in Kagoshima, within the Kyushu mainland, was reported by Hatsushima [30], after which those populations vanished [31]. One population indicated a common haplotype with the Goto Islands to that of the center of Nagasaki Mainland, was located in rocky places facing the sea. It seemed this population might be derived from seeds that were washed ashore.

To further define the processes of population distribution in these areas, we would have to analyze other genetic regions that allow the comparison of intraspecific variations and nuclear DNA. East China and the Korean Peninsula were connected by an ECS basin during the last Pleistocene, suggesting the possibility of rapid expansion in species distribution during this period [7]. Accordingly, the C. incana population of Mainland China may be a common haplotype distributed in the Korean Peninsula [32]. Additionally, the degree of separation in the populations between in Japan and in the Korean Peninsula would depend on whether the haplotype in Korean Peninsula is similar to Japanese haplotype or not. Future phylogenetic analysis would be necessary to estimate the periods of distribution in Japan by investigating wild individuals from the Korean Peninsula and Mainland China.

In conclusion, we confirmed the present natural environment of $C$. incana, which is an endangered species in Japan, and constructed its distribution map in West Kyushu. We confirmed the trend that the number of natural populations in the Nagasaki Mainland has been recently decreasing. Additionally, we investigated the genetic structure among 109 populations in West Kyushu, based on chloroplast DNA sequences. Twenty-two haplotypes were mainly classified into two groups by phylogenetic analysis. We speculated that the common ancestor of $C$. incana in Japan had diverged into two groups, after that the distribution expanded and has been maintained in each area. Furthermore, a high genetic diversity within the Goto Islands was indicated. We confirmed the populations of the indicated haplotypes that are distributed on the Koshikijima Islands and the Goto Islands in the Nagasaki Mainland, suggesting that a complicated distribution formation had occurred in this area. Additional comparisons of the genetic structure among natural populations in West Kyushu, and phylogenetic analysis by studying wild individuals from the Korean Peninsula and Mainland China, would offer useful information on the evolutionary history of $C$. incana.

\section{References}

[1] Avise, J.C., Arnold, J., Ball, R.M., Bermingham, E., Lamb, T., Neigel, J.E., Reeb, C.A. and Saunders, N.C. (1987) Intraspecific Phylogeography: The Mitochondrial DNA Bridge between Population Genetics and Systematics. Annual Reviews of Ecology and Systematics, 18, 489-522. http://dx.doi.org/10.1146/annurev.es.18.110187.002421

[2] Hewitt, G.M. (1996) Some Genetic Consequences of Ice Ages, and Their Role in Divergence and Speciation. Biological Journal of the Linnean Society, 58, 247-276. http://dx.doi.org/10.1111/j.1095-8312.1996.tb01434.x

[3] Comes, H.P. and Kadereit, J.W. (1998) The Effect of Quaternary Climatic Changes on Plant Distribution and Evolution. Trends in Plant Science, 3, 1360-1385. http://dx.doi.org/10.1016/S1360-1385(98)01327-2

[4] Medail, F. and Diadema, K. (2009) Glacial Refugia Influence Plant Diversity Patterns in the Mediterranean Basin. 
Journal of Biogeography, 36, 1333-1345. http://dx.doi.org/10.1111/j.1365-2699.2008.02051.x

[5] Kimura, M. (1996) Quaternary Paleogeography of the Ryukyu Arc. Journal of Geography, 105, 259-285. http://dx.doi.org/10.5026/jgeography.105.3_259

[6] Kimura, M. (2000) Paleogeography of the Ryukyu Islands. Tropics, 10, 5-24. http://dx.doi.org/10.3759/tropics.10.5

[7] Ota, H. (1998) Geographic Patterns of Endemism and Speciation in Amphibians and Reptiles of the Ryukyu Archipelago, Japan, with Special Reference to their Paleogeographical Implications. Researches on Population Ecology, 40, 189-204. http://dx.doi.org/10.1007/BF02763404

[8] Kimura, A. and Kimoto, K. (2006) History of the Inflow of the Warm Tsushima Current into the Sea of Japan between 3.5 and 0.8 Ma. Palaeogeography, Palaeoclimatology, Palaeoecology, 236, 355-366. http://dx.doi.org/10.1016/j.palaeo.2005.11.015

[9] Furukawa, M. and Fujitani, T. (2014) Comparative Study on Pleistocene Paleogeographic Maps of Ryukyu Arc. Bulletin of the Faculty of Science (University of the Ryukyus), 98, 1-8.

[10] Qian, H. and Ricklefs, R.E. (2000) Large-Scale Processes and the Asian Bias in Species Diversity of Temperate Plants. Nature, 407, 180-182. http://dx.doi.org/10.1038/35025052

[11] Harrison, S.P., Yu, G., Takahara, H. and Prentice, I.C. (2001) Palaeovegetation (Communications Arising): Diversity of Temperate Plants in East Asia. Nature, 413, 129-130. http://dx.doi.org/10.1038/35093166

[12] Nakanishi, H. (2010) Distribution and Ecology of Islet Biased Plants in Northern Kyushu, Japan. Vegetation Science, 27, 1-9.

[13] Park, Y.C., Kitade, O., Schwarz, M., Kim, J.P. and Kim, W. (2006) Intraspecific Molecular Phylogeny, Genetic Variation and Phylogeography of Reticulitermes speratus (Isoptera: Rhinotermitidae). Molecules and Cells, 21, 89-103.

[14] Itow, S. (1997) A Review of Phyto- and Vegetation Geography in the Japan-Korea Strait Region. Bulletin of the Faculty of Liberal Arts, Nagasaki University, Natural Science, 38, 25-51.

[15] Nakanishi, H. (1996) Plant Species with Northbound Distribution in Western-Kyushu, Japan: Definition, Composition and Origin. Acta Phytotaxonomica et Geobotanica, 47, 113-124.

[16] Itow, S. and Kawasato, H. (1988) The Distribution and Ecology of Caryopteris incana Maxim. (Verbenaceae) in Western Kyushu, Japan. Hikobia, 10, 135-143.

[17] Environment Agency of Japan (2000) Threatened Wildlife of Japan, Red Data Book 8, 2nd Edition. Japan Wildlife Research Center, Tokyo, 521.

[18] Ando, M., Watanabe, H., Matsubara, K. and Taniguchi, A. (2015) Intraspecific Phylogenetic Relationships of Caryopteris incana in the Tsushima Islands, Japan, Using DNA Sequence Analysis. American Journal of Plant Sciences, 14, 2361-2373. http://dx.doi.org/10.4236/ajps.2015.614239

[19] Nakamura, K., Denda, T., Kokubugata, G., Suwa, R., Yang, T.Y.A., Peng, C.I. and Yokota, M. (2010) Phylogeography of Ophiorrhiza japonica (Rubiaceae) in Continental Islands, the Ryukyu Archipelago, Japan. Journal of Biogeography, 37, 1907-1918. http://dx.doi.org/10.1111/j.1365-2699.2010.02342.x

[20] Shaw, J., Lickey, E.B., Schilling, E.E. and Small, R.L. (2007) Comparison of Whole Chloroplast Genome Sequences to Choose Noncoding Regions for Phylogenetic Studies in Angiosperms: The Tortoise and the Hare III. American Journal of Botany, 94, 275-288. http://dx.doi.org/10.3732/ajb.94.3.275

[21] Hall, T.A. (1999) BioEdit: A User-Friendly Biological Sequence Alignment Editor and Analysis Program for Windows 95/98/NT. Nucleic Acids Symposium Series, 41, 95-98.

[22] Tamura, K., Stecher, G., Peterson, D., Filipski, A. and Kumar, S. (2013) MEGA6: Molecular Evolutionary Genetics Analysis Version 6.0. Molecular Biology and Evolution, 30, 2725-2729. http://dx.doi.org/10.1093/molbev/mst197

[23] Clement, M., Posada, D. and Crandall, K.A. (2000) TCS: A Computer Program to Estimate Gene Genealogies. Molecular Ecology, 9, 1657-1659. http://dx.doi.org/10.1046/j.1365-294x.2000.01020.x

[24] Charlesworth, D. and Charlesworth, B. (1987) Inbreeding Depression and Its Evolutionary Consequences. Annual Review of Ecology and Systematics, 18, 237-268. http://dx.doi.org/10.1146/annurev.es.18.110187.001321

[25] Keller, L.F. and Waller, D.M. (2002) Inbreeding Effects in Wild Populations. Trends in Ecology and Evolution, 17, 230-241. http://dx.doi.org/10.1016/S0169-5347(02)02489-8

[26] Stephens, P.A., Sutherland, W.J. and Freckleton, R.P. (1999) What Is the Allee Effect? Oikos, 87, 185-190. http://dx.doi.org/10.2307/3547011

[27] Yano, O., Ikeda, H. and Hoshino, T. (2010) Phylogeography of the Japanese Common Sedge, Carex Conica Complex (Cyperaceae), Based on Chloroplast DNA Sequence Data and Chromosomal Variation. American Journal of Botany, 97, 1365-1376. http://dx.doi.org/10.3732/ajb.0900338

[28] Aoki, K., Suzuki, T., Hsu, T.W. and Murakami, N. (2004) Phylogeography of the Component Species of Broad- 
Leaved Evergreen Forests in Japan, Based on Chloroplast DNA Variation. Journal of Plant Research, 117, 77-94. http://dx.doi.org/10.1007/s10265-003-0132-4

[29] Ohi, T., Kajita, T. and Murata, J. (2003) Distinct Geographic Structure as Evidenced by Chloroplast DNA Haplotypes and Ploidy Level in Japanese Aucuba (Aucubaceae). American Journal of Botany, 90, 1645-1652. http://dx.doi.org/10.3732/ajb.90.11.1645

[30] Hatsushima, S. (1964) Plant of Kagoshima. Nature of Kagoshima, 35, 35-88.

[31] Sotoyama, S. (1980) Flora of Nagasaki. The Nagasaki Biological Society, Nagasaki, 312.

[32] Lee, J.H., Lee, D.H. and Choi, B.H. (2013) Phylogeography and Genetic Diversity of East Asian Neolitsea sericea (Lauraceae) Based on Variations in Chloroplast DNA Sequences. Journal of Plant Research, 126, 193-202. http://dx.doi.org/10.1007/s10265-012-0519-1 